\title{
ARTICULAÇÃO ENTRE APRENDIZAGEM BASEADA EM PROBLEMAS E ANÁLSE FÍLMICA: UMA PROPOSTA DE ENSINO A PARTIR DO FILME $A$ FÁBRICA DE SONHOS
}

\author{
David Silva Franco ${ }^{1}$ \\ Gérber Lúcio Leite ${ }^{2}$ \\ Venilson Luciano Benigno Fonseca ${ }^{3}$
}

\section{RESUMO}

Este estudo tem como objetivo propor uma prática pedagógica que articula Aprendizagem Baseada em Problemas (ABP) e análise fílmica, tomando como recurso audiovisual o longametragem A Fábrica de Sonhos. Com a sociedade ficando cada vez mais complexa e com constantes transformações produtivas, aceleradas pelas inovações tecnológicas, considera-se que o ensino em Administração se situa em contextos dinâmicos e mutáveis. Em tal cenário, a postura docente de estimular metodologias ativas de aprendizagem, favorecendo o pensamento crítico dos estudantes, a fim de que analisem os problemas considerando os seus múltiplos fatores, tende a propiciar a construção mútua de conhecimentos de forma mais efetiva. A ABP é uma das metodologias utilizadas para fomentar o diálogo e as descobertas dos estudantes, por meio de conhecimentos interdisciplinares. Já a análise fílmica auxilia didaticamente o ensino em Administração, ao provocar nos estudantes estímulos cognitivos por meio da aprendizagem social, atribuindo sentido na relação dos conteúdos das disciplinas com o contexto sócio-histórico. Como metodologia da pesquisa, foi realizada a análise fílmica e elaborada a proposta pedagógica embasada na ABP. Como resultado, tem-se a análise fílmica de A Fábrica de Sonhos, a identificação dos problemas ficcionais apresentados no longa

\footnotetext{
${ }^{1}$ Doutor em Administração pela Universidade Federal de Minas Gerais, professor EBTT no Instituto Federal de Minas Gerais e pesquisador do NEC-TraMa.

2 Mestre em Administração pela Faculdade Novos Horizontes e professor EBTT no Instituto Federal de Minas Gerais.

3 Doutor em Geografia Humana pela Universidade Federal de Minas Gerais e professor EBTT no Instituto Federal de Minas Gerais.
} 
e sua correspondência com teorias da Administração, além de serem feitas orientações para a aplicação da proposta interdisciplinar de ensino.

Palavras-Chave: Análise Baseada em Problemas; Análise Fílmica; Teorias da Administração; Ensino Interdisciplinar; Metodologias Ativas de Aprendizagem.

\section{ARTICULACIÓN ENIRE EL APRENDIZAJE BASADO EN PROBLEMAS Y EL ANÁUSIS CINEMATOGRÁFICO: UNA PROPUESTA DIDÁCTICA BASADA EN LA PELÚCULA KINKY BOOTS}

\section{RESUMEN}

Este estudio tiene como objetivo proponer una práctica pedagógica que articule el Aprendizaje Basado en Problemas (ABP) y el análisis cinematográfico, utilizando el largometraje Kinky Boots como recurso audiovisual. Con la sociedad cada vez más compleja y con constantes transformaciones productivas, aceleradas por las innovaciones tecnológicas, se considera que la docencia en Administración se sitúa en contextos dinámicos y cambiantes. En tal escenario, la postura docente de estimular metodologías de aprendizaje activo, favoreciendo el pensamiento crítico de los estudiantes, con el fin de analizar la problemática considerando sus múltiples factores, tiende a promover la construcción mutua de conocimientos de manera más efectiva. El $\mathrm{ABP}$ es una de las metodologías utilizadas para fomentar el diálogo y los descubrimientos de los estudiantes, a través del conocimiento interdisciplinario. El análisis de películas, por su parte, enseña didácticamente la docencia en Administración, provocando a los estudiantes con estímulos cognitivos a través del aprendizaje social, dando sentido a la relación entre los contenidos de las disciplinas y el contexto socio-histórico. Como metodología de investigación se realizó un estudio observacional de la película y se elaboró la propuesta pedagógica basada en ABP. Como resultado, está el análisis cinematográfico de Kinky Boots, la identificación de los problemas de ficción presentados en el largometraje y su correspondencia con las Teorías de la Administración, además de proporcionar pautas para la aplicación de la propuesta didáctica interdisciplinar. La propuesta pedagógica presentada es aplicable tanto a la educación técnica como a la superior, variando sus resultados según el nivel de conocimientos y madurez de la clase.

Palabras clave: Análisis Basado en Problemas; Análisis Cinematográfico; Teorías de la administración; Enseñanza interdisciplinaria; Metodologías de aprendizaje activo.

\section{ARTICULATION BETWEEN PROBLEM-BASED LEARNING AND FILM ANALYSIS: A TEACHING PROPOSAL BASED ONTHE FILM KINKYBOOTS}

\section{ABSTRACT}

This study aims to propose a pedagogical practice that combines Problem-Based Learning (PBL) and film analysis, using the feature film Kinky Boots as an audiovisual resource. With society getting more and more complex and with constant productive transformations, accelerated by 
technological innovations, it is considered that teaching in Administration is situated in dynamic and changing contexts. In such a scenario, the teaching posture of stimulating active learning methodologies, favoring students' critical thinking, in order to analyze the problems considering their multiple factors, tends to promote the mutual construction of knowledge more effectively. PBL is one of the methodologies used to foster students' dialogue and discoveries, through interdisciplinary knowledge. Film analysis, on the other hand, supports didactically teaching in administration, by provoking students with cognitive stimuli through social learning, giving meaning to the relationship between the contents of the disciplines and the socio-historical context. As a research methodology, an observational study of the film was carried out and the pedagogical proposal based on PBL was elaborated. As a result, there is the film analysis of Kinky Boots, the identification of fictional problems presented in the feature and its correspondence with Administration theories, in addition to providing guidelines for the application of the interdisciplinary teaching proposal. The pedagogical proposal presented is applicable to both technical and higher education, varying its results according to the level of knowledge and maturity of the class.

Keywords: Problem-Based Analysis; Film Analysis; Administration Theories; Interdisciplinary Teaching; Active Learning Methodologies.

\section{INTRODUÇÃO}

No âmbito das ciências sociais, todo conhecimento representa modos de ser e viver, seja de modo prescritivo (como se deveria viver, interagir e produzir), seja de modo descritivo (como se vive, se interage e se produz). Assim, não há ensinamentos que sejam livres de ideologia, isto é, que não atue para a formação de um sistema de pensamento social que tenha o potencial de conformar as práticas sociais. Um suposto conhecimento neutro, alegadamente livre de ideologia, já pode ser, em si mesmo, considerado um instrumento ideológico de manutenção das práticas sociais vigentes, reforçando o status quo. Neste sentido, os professores têm um papel muito importante na formação dos sujeitos sociais, visto que atuam diretamente sobre como os aprendizes compreendem a sociedade onde vivem.

Importante considerar que, se o professor contribui à formação do pensamento social, também ele foi previamente formado por sistemas de valores da sociedade - ainda que muitos destes valores possam, por vezes, mais prejudicar do que favorecer ao pensamento crítico e à uma concepção inclusiva de justiça social. Conforme exposto por Pedro Goergen (2007), é importante que o professor eduque seus alunos levando-os a refletirem sobre quais 
são os valores com os quais eles podem se comprometer e se responsabilizar. Ainda segundo o autor:

As crianças e os jovens passam grande parte de sua vida na escola. Nesse tempo forma-se sua sensibilidade, sua maneira de pensar e de julgar, se moldam seus conceitos e representações, se enraízam atitudes e comportamentos. Todo esse desenvolvimento que acontece ao longo dos anos escolares representa a constituição da identidade do sujeito com suas diferentes, mas complementares faces do epistêmico, do estético e do ético. Mesmo que defendêssemos o ponto de vista de que a educação não deveria ocupar-se da formação moral dos seus alunos, seria impossível negar que, de uma forma ou de outra, no contexto escolar das relações professor/aluno, dos livros didáticos, das avaliações, estariam sendo transmitidos ideais e imagens de homem, de mundo, de relacionamento, de normas e valores. A influência moral sobre os alunos é impossível de ser evitada no ambiente escolar (GOERGEN, 2007, p. 746).

No cenário contemporâneo temos presenciado a gradativa complexificação da sociedade, que passa a incorporar massivamente as inovações tecnológicas em períodos cada vez mais curtos. Ao considerarmos o contexto organizacional das empresas faz-se importante observar que as decisões estratégicas, táticas e operacionais se dão em um contexto histórico, político, econômico e cultural que abarcam um grande universo de possibilidades e dilemas éticos. Entendemos que o ensino em Administração, uma ciência social aplicada, deve estar fortemente articulado às ciências humanas, buscando compreender como os seres sociais se organizam e materializam seus interesses no âmbito produtivo-econômico. Dessa forma, partimos da concepção de que quaisquer técnicas administrativas estão situadas em contextos sociais dinâmicos e sua aplicação envolve a análise de problemas multifatoriais.

No intuito de melhor preparar os estudantes para lidar com esse ambiente dinâmico, diversos estudos (VERSIANI; FACHIN, 2007; FRANCO; PAIVA; HELMOND, 2015; URIAS; AZEREDO, 2017; SOAREAS et al., 2019; MUNCK; BORGES, 2020) têm destacado a relevância da utilização de metodologias ativas de ensino no campo da Administração. Para tanto, as possibilidades de aplicação de estratégias de ensino são inúmeras, abrangendo uma grande variedade de recursos e de pressupostos epistemológicos. Ainda assim, é possível destacar 
que há certo consenso quanto à necessidade de elas estimularem a autonomia, a liberdade de pensamento, a participação experiencial dos aprendizes, o que dá o caráter diferenciador da passividade atribuída aos estudantes nas metodologias tradicionais (que tendem a destinálos o papel de meros receptadores de informação).

Considerando o vasto arcabouço de metodologias ativas, uma que tem ganhado relevante espaço é a Aprendizagem Baseada em Problemas (ABP) - uma tradução da originalmente denominada Problem-Based Learning (PBL). 0 princípio básico da ABP é o de apresentação de situações complexas, reais ou fictícias, que exigem decisões ponderadas para que se possa traçar soluções aos problemas apresentados. Quando se adotada a ABP, esperase que os estudantes, a partir de conhecimentos interdisciplinares, envolvam-se em diálogos e reflexões que os conduzam a descobertas, o que propicia melhor fixação da aprendizagem (GUEDES; ANDRADE; NICOLINI, 2015).

Outro recurso alternativo para diversificação das práticas de ensino é a análise fílmica. De acordo com Fleury e Sarsur (2007):

[...] utilizar um filme como instrumento de compreensão dos conceitos [...] passa pela convicção de que realidade e fiç̧ão aproximam-se, e que a busca por semelhanças e divergências entre ambas pode ser uma forma bastante adequada de análise da utopia sobre o mundo cotidiano real (FLEURY \& SARSUR: 2007, Pág. 06).

Já para Freitas e Leite (2015), a arte pode ser um instrumento que permite a modificação da consciência e a emersão de novos modos sensíveis de trabalhar, ou seja, ao se incorporar a percepção visual proveniente de filmes e sua correspondente perspectiva estética, amplia-se o arcabouço disponível para a análise de fenômenos organizacionais e de atuação prática.

Partindo das premissas supracitadas, nossa pesquisa objetivou propor uma prática pedagógica que articula Aprendizagem Baseada em Problemas e análise fílmica, tomando como recurso audiovisual o longa-metragem A Fábrica de Sonhos. Não identificamos na literatura acadêmica (considerando a base de periódicos online SciELO e Spell) pesquisas 
predecessoras que tenham analisado ambos os temas de forma integrada. Destarte, o presente trabalho representa uma oportunidade para a inauguração desta articulação específica, bem como um convite para que mais pesquisas avancem nesta possibilidade. $\mathrm{Na}$ proposta que elaboramos, foi valorizada a interdisciplinaridade, a importância das reflexões éticas para a tomada de decisão no campo da Administração e a análise sócio-histórica para a compreensão de fatores macroestruturais que atuam sobre a conformação do cenário organizacional.

\section{FUNDAMENTAÇÃO TEÓRICA}

Para a elaboração da proposta de ensino que embasa esse artigo, foi realizada uma revisão da literatura sobre a Aprendizagem Baseada em Problemas e sobre a análise fílmica. Nesta seção, apresentamos um panorama dos temas, sem esquivarmo-nos das necessárias críticas que advieram com a análise de ambos.

\subsection{Aprendizagem Baseada em Problemas: conceito e crítica}

Diversas pesquisas (CASALE; KURI; SILVA, 2011; BOROCHOVICIUS; TORTELLA, 2014; GUEDES, ANDRADE, NICOLINI, 2015) apontam que a Aprendizagem Baseada em Problemas (ABP) foi desenvolvida no início da década de 1970, na escola de medicina da Universidade de McMaster, situada no Canadá. Em partes, o modelo foi inspirado pelo método de estudos de caso da instituição estadunidense Harvard Business School, que envolvia a discussão de casos práticos para a consolidação do conhecimento nos últimos períodos do curso. Em McMaster, contudo, a concepção inicial visava que os conceitos fossem elaborados após a compreensão da situação problema pelos estudantes. No Brasil, também os cursos de medicina são pioneiros na utilização da ABP como método de ensino e aprendizagem.

Conforme Padua Junior et al. (2014, p. 300), a ABP tem como principais características “a organização temática envolvendo problemas, a integração interdisciplinar entre conceitos teóricos e práticos e a ênfase no desenvolvimento cognitivo". Com efeito, os autores indicam que a situação problema deve direcionar o processo de apropriação dos conhecimentos pelos 
estudantes e, partindo do princípio de que o desenvolvimento das soluções não aponta para caminhos únicos, os aprendizes precisam, a partir do diálogo em equipe, chegarem a um consenso que integrem posições divergentes.

De acordo com Borochovicius e Tortella (2014), a ABP tem a potencialidade de atender as necessidades tanto dos discentes quanto dos docentes. Em relação aos primeiros, destacam que o método permite maior contato dos estudantes com os possíveis problemas que irão se deparar em suas futuras profissões, além de os estimularem a "aprender a aprender", tornando-os mais críticos e aptos a tomarem decisões importantes. Quanto aos docentes, os autores dissertam quanto ao estímulo à maior busca pela interdisciplinaridade, tornando-os mais aptos à promoção da aprendizagem a partir de um conteúdo que faz maior sentido aos futuros profissionais. Destacam ainda o retorno que a ABP pode trazer à sociedade, "pois em função da alta competitividade, concorrência e um cenário globalizado e repleto de rápidas mudanças no mundo do trabalho, [ela] recebe um profissional apto a buscar soluções condizentes com a realidade e suas necessidades" (BOROCHOVICIUS; TORTELLA, 2014, p. 273).

Ao analisar a gama de trabalhos acadêmicos que propõem a aplicação da $A B P$, são notórios o empobrecimento do debate epistemológico e o processo de ocultamento crítico das teorias que, historicamente, deram base às propostas que visam maior autonomia e conscientização do meio social no processo formativo. Como a origem da ABP (e de suas posteriores teorizações) advém de uma necessidade e enfoque essencialmente empíricos, há um certo apagamento das diversas correntes teóricas que questionaram o ensino tradicional - não apenas por conta da menor absorção de conhecimento pelo estudante, mas pela falta de questionamento das relações de poder sobre as estruturas formativas que impõem determinada postura escolar. Tomando por base os princípios defendidos por pesquisadores que propõem a $\mathrm{ABP}$, notamos significativas correspondências com os pressupostos vigentes na concepção epistemológica do construtivismo (que embasa a pedagogia construtivista) e na obra de Paulo Freire A pedagogia do oprimido. Contudo, os pontos em que ambas repelem o positivismo - doutrina filosófica das ciências sociais que tende a hipervalorizar a 
quantificação de comportamentos observáveis e/ou de percepções autorrelatadas para a compreensão das leis sociais, isolando os fenômenos de explicações sócio-históricas - e a hierarquização rígida do ambiente escolar pouco aparecem no debate.

Sobre o construtivismo, Arias e Yera (1996, p. 13-14) apontam que:

[ele] não é método, mas tem implicações metodológicas para a prática docente: a importância do grupo em correspondência com o caráter social do processo de aprendizagem e de formação da personalidade; o papel do professor como "instigador" da aprendizagem; a necessidade de combinar certa disciplina e uma rotina de trabalho escolar (com objetivos claramente definidos) com um ambiente de relativa liberdade para as crianças; o valor fundamental da satisfação e da motivação (do "desejo") de educadores e educandos para o sucesso da aprendizagem; a relevância dos erros como subsídios para orientar a ação do aluno na sala de aula; o enfoque da criança como sujeito da educação e não mais como objeto passivo dela; a significação do diálogo inteligente para formar e desenvolver os conceitos científicos nas crianças, etc.

A pedagogia construtivista é uma proposta democrática. Existe na verdade, determinada correlação entre o desenvolvimento da inteligência e a organização da vida individual e social sobre bases democráticas, racionais. Se cada indivíduo constrói seu mundo psíquico de modo sui generis, irrepetível, então cada criança representa uma riqueza em si, e é, por tanto, merecedora de respeito e da mais alta consideração. Além disso, no diálogo e na cooperação temos também a possibilidade de enriquecermos com a forma específica em que o outro construiu determinado conhecimento. Tolerância face à diversidade psicossocial, o respeito à individualidade da criança, ao direito e às opiniões alheias, liberdade, ausência de autoritarismo, igualdade, cooperação, consciência e exercício da cidadania. Tal é o que emana do paradigma teórico construtivista aplicado à educação.

Nesse sentido, percebemos a aproximação entre a Aprendizagem Baseada em Problemas e os paradigmas do construtivismo (embora autores que suscitam a ABP raramente mencionem isso). Já na teoria da educação de Paulo Freire (2005), o autor se contrapõe a todos os principais pressupostos educacionais do que ele denomina pedagogia bancária - concepção dos aprendizes como receptadores de informações, inaptos, seguidores 
de prescrições, aqueles que se adaptam ao conteúdo programático rígido e é objeto do sujeito educador - e defende uma educação como prática de liberdade - aquela que é integrada ao contexto sócio-histórico do aprendiz, que conscientiza sobre o lugar dele no mundo, que incentiva sua liberdade de pensamento, que se embasa em relações dialógicas e que serve de instrumento para superação das relações de dominação que persistem na estrutura social. Por isso, para Freire, um programa educacional que visa a prática libertadora deve visar a investigação mútua (entre educador e educandos) das temáticas geradoras, isto é, temáticas que estimulam a gradativa superação da parcialidade do conhecimento (subjetividades particulares, limites disciplinares, aspirações despertadas pelo ato aprender) rumo a uma apreensão cognitiva mais holística e integradora.

Esta [a temática geradora], à base da qual se pretende elaborar o programa educativo, em cuja prática educadores-educandos e educandos-educadores conjuguem sua ação cognoscente sobre o mesmo objeto cognoscível, tem de fundar-se, igualmente, na reciprocidade da ação. E agora, da ação mesma de investigar.

A investigação temática, que se dá no domínio do humano e não no das coisas, não pode reduzir-se a um ato mecânico. Sendo processo de busca, de conhecimento, por isto tudo, de criação, exige de seus sujeitos que vão descobrindo, no encadeamento dos temas significativos, a interpenetração dos problemas.

Por isto é que a investigação se fará tão mais pedagógica quanto mais crítica e tão mais crítica quanto, deixando de perder-se nos esquemas estreitos das visões parciais da realidade, das visões "focalistas" da realidade, se fixe na compreensão da totalidade.

Assim é que, no processo de busca da temática significativa, já deve estar presente a preocupação pela problematização dos próprios temas. Por suas vinculações com outros. Por seu envolvimento histórico-cultural (FREIRE, 2005, p. 116).

Como podemos perceber, a discussão sobre metodologias ativas de aprendizagem, na qual se encontra também a defesa da Aprendizagem Baseada em Problemas, apresenta significativo potencial de alinhamento com a prática pedagógica construtivista e com a teoria freireana. 


\subsection{Análise fílmica como recurso para práticas de ensino e aprendizagem}

A utilização de recursos audiovisuais para o auxílio de práticas de ensino e aprendizagem tem sido frequente nas últimas décadas. Conforme Mendonça e Guimarães (2008), a utilização de filmes pode ser uma grande aliada aos docentes, visto o potencial de estimular processos cognitivos aos estudantes por meio da aprendizagem social, isto é, da aprendizagem comportamental a partir da observação contextual de outros sujeitos. Por meio da análise da arte visual, podemos compreender determinados elementos de atribuição de sentidos que se fazem presentes em determinado contexto sócio-histórico, apresentando indícios dos valores e comportamentos de uma época.

Na concepção de Katia Abud (2003), dentre os meios de comunicação, o cinema é o que mais tem despertado a atenção dos professores. Fatores como a grande atração que os filmes despertam sobre os estudantes, sua acessibilidade e a possibilidade de diversificação das tradicionais aulas de exposição oral são apontados como relevantes para essa atração. Para a autora, as “imagens merecem estar em sala de aula porque sua leitura nunca é passiva", visto que "provocam uma atividade psíquica intensa feita de seleções, de relações entre elementos da mesma obra, mas também com outras imagens e com representações criadas e expressas por outras formas de linguagem" (ABUD, 2003, p. 188).

No campo da Administração, entre as pesquisas que apresentam propostas de análise de filmes como auxílio didático, destacamos as seguintes: Fleury e Sarsur (2007) propõem o ensino da gestão por competências com o auxílio da análise fílmica de "Nenhum a Menos"; Mendonça e Guimarães (2008) apresentam um relato sobre a utilização de filmes na graduação e na pós-graduação, destacando o êxito dessas atividades e sugestões didáticas; Maciel e Helal (2017) propõem uma atividade didática sobre o assédio moral, a partir da análise fílmica de "O diabo veste Prada"; já Barros, Miranda e Rodrigues (2017) analisam como a animação "Monstros S.A" pode ser adotada para, a partir de metáforas e interpretações, serem realizadas reflexões sobre alguns fenômenos organizacionais. Estes últimos apontam ainda que: 
A arte como recurso didático é uma experiência mais suave em relação às vivências do mundo real. Metaforiza as experiências reais e, como representação simbólica, ajuda a manifestar não só as emoções, mas também o entendimento. Administração é um campo do conhecimento que engloba teorias e práticas, que, aliado à arte, apresenta múltiplas possibilidades de ensino. Utilizar o cinema, como via de compreensão e de reflexão sobre as organizações, é oferecer, ao estudante, professor e pesquisador, um novo olhar, aquele que indaga e questiona, um olhar atento e inconformado (BARROS, MIRANDA; RODRIGUES, 2017, p. 177).

Acrescentamos que a utilização de filmes para a exposição de exemplos conceituais aos discentes, por um lado, embora possa facilitar a explicação pelo professor, por outro, demanda grande responsabilidade e preparação do docente. Como as películas trazem diversas representações situacionais verossímeis com a realidade (incluindo aquelas que simplificam e/ou distorcem as explicações do real ali caricaturado), é importante que o professor esteja preparado para conduzir debates com os estudantes para, inclusive, questionar estereótipos, discriminações, naturalização da violência, dentre outros pontos que, por vezes, aparecem despretensiosamente nas obras de ficção. Assim, a capacitação docente, no intuito de apurar a análise observacional e identificar conteúdos latentes nas entrelinhas dos discursos, pode ser de grande valia para tornar a prática pedagógica mais efetiva e guiar os estudantes no desenvolvimento do pensamento crítico.

\section{METODOLOGIA DA PESQUISA}

A presente pesquisa é do tipo descritivo, de abordagem qualitativa. Foi realizado um estudo observacional para a análise fílmica da obra ficcional A Fábrica de Sonhos. Este filme foi escolhido em função de sua rica narrativa, a qual apresenta diversas possibilidades reflexivas e de aplicação ao ensino em Administração. Como a obra é centrada no ambiente organizacional de uma fábrica de sapatos, abrangendo variadas decisões e ações do personagem gestor-proprietário da empresa, foi possível a utilização deste material para a elaboração de uma proposta pedagógica embasada na Aprendizagem Baseada em Problemas. 
Na proposição de Isboli, Pépece e Gaiotto (2017), a qual adotamos, a análise fílmica nas ciências sociais aplicadas pode ser dividida em cinco momentos, aqui expostos resumidamente: (1) caracterização dos antecedentes, quando são observados o gênero e subgênero da obra, o registro temporal em que o filme é gravado e a época histórica retratada, os temas abrangidos e a finalidade da representação; (2) elementos componentes, analisando-se o histórico do diretor da obra e da construção de personagens principais que ele já produziu; (3) contato efetivo com o filme, momento em que devem ser analisados o espaço onde a exposição do filme ocorre aos expectadores (cinema, escola, empresa, casamento), visto que o local poderá ter influência sobre as interpretações dos expectadores sobre o vídeo; (4) mensagens elaboradas, quando a análise se volta para o retrato social, os estereótipos representados, o núcleo principal e seus valores, as problemáticas expostos, a interação dos personagens, o desenvolvimento do filme, os momentos históricos etc.; e (5) efeitos consequentes, analisando-se a reflexão gerada pelo filme, suas ações de divulgação, as derivações produzidas e as eventuais premiações que ele tenha recebido.

0 percurso metodológico de nosso estudo foi dividido em três partes: (1) análise fílmica da obra, articulando o enredo aos principais problemas administrativos que o personagem protagonista vivencia; (2) análise dos problemas identificados a luz da literatura científica no campo das Teorias da Administração; (3) consolidação da análise fílmica com uma proposta pedagógica embasada na $\mathrm{ABP}$, sugerindo uma prática de ensino que é aplicável tanto ao ensino técnico em Administração quanto ao ensino superior (visto que é a própria maturidade e o conhecimento prévio dos estudantes que darão o tom do grau de complexidade do resultado da aplicação da atividade). Os resultados são apresentados na próxima seção.

\section{EXPOSIÇÃO DOS RESULTADOS}

Conforme exposto na seção anterior, os resultados da pesquisa estão divididos em três partes. Iniciaremos com a análise fílmica da obra supramencionada. 


\subsection{Análise e enredo do filme "A Fábrica de Sonhos"}

Antes de expormos o enredo do longa-metragem, apresentamos no Quadro 1 uma síntese da análise fílmica de A Fábrica de Sonhos, denominado Kinky Boots na língua original da obra, seguindo o arcabouço proposto por Isboli, Pépece e Gaiotto (2017), com ênfase nos aspectos mais relevantes para o propósito desse artigo.

Quadro 1 - Síntese da análise fílmica de A Fábrica de Sonhos

\begin{tabular}{|c|c|}
\hline $\begin{array}{c}\text { Elementos da } \\
\text { análise }\end{array}$ & Resultados \\
\hline $\begin{array}{l}\text { 1. } \\
\text { Caracterização } \\
\text { dos } \\
\text { antecedentes }\end{array}$ & $\begin{array}{l}\text { Trata-se de uma comédia musical, lançada em } 2005 \text {. } \\
\text { A obra é baseada na história real de Steve Pateman, que assumiu a gestão } \\
\text { de uma fábrica familiar de calçados em Northamptonshire, na Inglaterra. Na } \\
\text { verdadeira história, Steve Pateman ingressou na empresa da família em } \\
1979 \text { e, em } 1993 \text {, assumiu o cargo de diretor administrativo. Na década de } \\
1990 \text {, próximo de fechar sua fábrica, Steve recebe a demanda para produzir } \\
\text { botas femininas em tamanhos especiais, as quais seriam vendidas em uma } \\
\text { loja que atendia ao público de drag queens e transgênero. A mudança no } \\
\text { empreendimento foi um sucesso. } \\
\text { Os principais temas que o filme aborda são: sucessão em empresa familiar; } \\
\text { preconceito em relação à expressão de gênero e sexualidade; mudanças nos } \\
\text { ambientes de negócios; inovação empresarial. }\end{array}$ \\
\hline $\begin{array}{l}\text { 2. Elementos } \\
\text { componentes }\end{array}$ & $\begin{array}{l}\text { O filme foi dirigido Julian Jarrold e foi escrito por Tim Firth e Geoff Deane. } 0 \\
\text { histórico do diretor e escritores do filme não indicam relação com a análise } \\
\text { almejada neste trabalho. }\end{array}$ \\
\hline $\begin{array}{l}\text { 3. Contato } \\
\text { efetivo com o } \\
\text { filme }\end{array}$ & $\begin{array}{l}\text { Na proposta que apresentamos, o contato com o filme ocorrerá em sala de } \\
\text { aula ou em auditório escolar. A obra tem duração de } 106 \text { minutos de } \\
\text { exposição, logo, é recomendado que seja separado o período suficiente para } \\
\text { a apresentação do filme completo, sem interrupções. Por ser uma obra } \\
\text { artística utilizada como parte de uma prática pedagógica, é importante que } \\
\text { o docente converse previamente com os estudantes, ressaltando a } \\
\text { importância de eles terem um "olhar analítico" ao assistirem o filme, } \\
\text { buscando relacioná-lo ao conteúdo teórico já visto em aulas. }\end{array}$ \\
\hline
\end{tabular}




\begin{tabular}{|c|c|}
\hline $\begin{array}{l}\text { 4. Mensagens } \\
\text { elaboradas }\end{array}$ & $\begin{array}{l}\text { Os principais personagens e seus estereótipos retratados no filme são: } \\
\text { - Sr. Price (pai): dono e gestor de empresa Sapatos Price, apresenta } \\
\text { grande centralização, paternalismo e tradicionalismo na gestão da } \\
\text { fábrica de calçados. Almeja passar a tradição da gestão dos negócios ao } \\
\text { seu filho. } \\
\text { - Charlie Price (filho): jovem inseguro e atrapalhado, formado em } \\
\text { marketing e sem grandes aspirações de seguir nos negócios da família. } \\
\text { - Lola: transgênero e drag queen, é idealizadora e performer em } \\
\text { apresentações artísticas e musicais em uma boate londrina. Torna-se } \\
\text { estilista dos modelos de sapatos que representam a mudança dos } \\
\text { negócios da Sapatos Price. } \\
\text { - Don: empregado da fábrica com postura rústica e machista, apresenta } \\
\text { relevante liderança informal entre a equipe de empregados da fábrica. } \\
\text { A obra transmite as seguintes mensagens principais: } \\
\text { - É importante a mudança de mentalidade, o trabalho em equipe, a } \\
\text { inovação e o acompanhamento de novas tendências para o sucesso dos } \\
\text { negócios. } \\
\text { - É importante o respeito às diferenças e a empatia para estabelecer um } \\
\text { clima de confiança e colaboraçáo, que refletem na construção de } \\
\text { propósito comum. } \\
\text { - A postura das lideranças formais e informais refletem fortemente na } \\
\text { cultura organizacional e na atitude dos membros da organização. }\end{array}$ \\
\hline $\begin{array}{l}\text { 5. Efeitos } \\
\text { consequentes }\end{array}$ & $\begin{array}{l}\text { Chiwetel Ejiofor, o intérprete de Lola, foi indicado ao prêmio Globo de Ouro, } \\
\text { na categoria de melhor ator de comédia ou musical. } \\
\text { Em 2012, a história de Kinky Boots se tornou um teatro musical em Chicago. } \\
\text { A partir de } 2013 \text {, teve a sua estreia como um teatro musical da Broadway, } \\
\text { tornando-se um grande sucesso e fazendo um tour por diversos países. }\end{array}$ \\
\hline
\end{tabular}

Fonte: Elaboração própria, a partir de informações obtidas em veículos jornalísticos diversos

O filme A Fábrica de Sonhos apresenta no enredo a história de um jovem, Charlie Price, que assume, após a morte de seu pai, a direção da Fábrica de Sapatos Price - um negócio que tem perpetuado na família por gerações. Inicialmente, o filme retrata as aspirações do Sr. Price, o então diretor, educando desde a infância de seu filho Charlie na preparação para que ele o suceda e perenize o negócio, cujo produto principal é o sapato modelo Oxford.

Charlie Price segue uma carreira diferente da pretendida pelo Pai, formando-se em Marketing, em vez de se interessar em assumir a gestão da fábrica. No momento em que vai se despedir dos empregados da fábrica, pois está de mudança para outra cidade, ele está calçando tênis - em clara contraposição com o Pai, que está com sapatos Oxford demonstrando assim que não está plenamente devoto à cultura organizacional da empresa. É 
perceptível que é uma cultura moldada pelo seu principal líder, pelos rituais e pressupostos básicos identificados na cena. Ressalta-se que o maquinário, os produtos e os processos produtivos não foram modernizados, demonstrando grande apego à tradição e pouco apreço às expectativas dos varejistas e aos possíveis novos perfis de consumidores.

Após o falecimento do Pai, Charlie Price retorna à sua cidade e assume a diretoria da fábrica, que está em franca decadência. Os empregados desdenham do sucessor, mas estão ansiosos para conhecer o estilo de gestão a ser implantado. 0 novo diretor, ao visitar seu principal cliente (que gerencia uma loja de revenda de calçados), descobre que a Fábrica de Sapatos Price produzia sem considerar a demanda como ponto de partida para elaboração do plano de abastecimento, isto é, seus produtos já não atendiam mais ao mercado consumidor varejista. 0 gerente da loja varejista compara os produtos que revende com os calçados que Charlie o apresenta. Charlie, espantado com a baixa qualidade dos produtos concorrentes aos seus, questiona: “- Mas estes produtos são péssimos! Os calçados Price foram feitos para durar uma vida toda! Estes daqui, em seis meses o cliente já terá que comprar um novo”. Ao que o gerente responde: “- Sim. E isso não é maravilhoso?”.

Após tomar ciência da situação próxima à falência da empresa, que seguia produzindo mesmo não tendo a quem vender, Charlie inicia um processo de reestruturação da força de trabalho, demitindo vários empregados - a prática de gestão mais simples de redução de custos, mas a de maior impacto organizacional.

Na viagem ao seu principal cliente, Charlie conhece ainda, por acaso, uma drag queen chamada Lola - pelas situações apresentadas no filme, pressupõe-se que Lola seja também transgênero, pois incorpora a performatividade (BUTLER, 2003) feminina não apenas nos espetáculos artísticos, mas também no cotidiano. Após este contato, Charlie decide testar a mudança de seu produto, passando a fabricar para um novo nicho de mercado: botas femininas para pessoas com estrutura corporal masculina. Identificando que as drag queens tinham muitos problemas com calçados femininos que não suportavam bem o seu peso, estragando os calçados com facilidade, Charlie decide fazer uma bota que pudesse atender bem a este público. Contudo, o protótipo da bota que Charlie apresenta foi imediatamente 
rechaçado por Lola. A bota era viável tecnicamente, mas seu design não atendia a imagem que este produto idealmente deveria transmitir. Após receber um desenho feito por Lola sobre o que ela esperava de uma bota, Charlie percebe as habilidades da artista e a convida para ser designer da fábrica, envolvendo-a na produção das botas que seriam apresentadas em uma feira de moda em Milão.

Após exigir muita qualidade, agilidade e horas extras de seus empregados, há uma deterioração do clima organizacional. Sentindo-se esgotados e desmotivados para seguir o ritmo imposto por Charlie, os empregados desistem de manter seu empenho para entregar os novos produtos antes do prazo necessário para a participação na Feira de Milão. Percebe-se que a gestão da empresa não estimula um senso de propósito comum na organização. Todas as principais decisões da empresa estão centralizadas no seu gestor principal. Importantes propostas sobre os rumos da empresa foram feitas por empregados - como a necessidade de mudança do produto e a forma de produzir as botas utilizando hastes de ferro -, contudo, foram sugestões não solicitadas pelo gestor. Os empregados apenas retomam o comprometimento para entregar os produtos a tempo com o convencimento feito por Don, um empregado que é um líder informal e de comportamento embrutecido. Após todos os empregados entenderem os objetivos e os riscos assumidos por Charlie, que penhora sua casa para fazer os investimentos necessários à produção, eles se organizam para produzir as botas com qualidade e em tempo para exposição na Feira de Milão. Essa penhora de recursos da pessoa física (Charlie) para resolver as necessidades da pessoa jurídica (Fábrica Price) demonstra o imbricamento entre a empresa familiar e seu gestor, indicando que o profissionalismo e a contabilidade empresarial não se encontram plenamente desenvolvidos. Para o desfile na feira, Charlie inova e ousa novamente com o show de drag queens, em vez de modelos tradicionais, o que torna a exposição um sucesso.

Apresentadas as análises iniciais do enredo da obra, partimos para os problemas organizacionais identificados na representação artística. 


\subsection{Problemas identificados e sua correspondência com Teorias da Administração}

Um dos grandes problemas na gestão da Fábrica de Sapatos Price era a ausência de planejamento. A empresa, quando planeja seus rumos (estratégicos, táticos e operacionais), faz uma reflexão tão completa quanto possível da realidade, analisando seus processos e buscando identificar seus pontos fortes, pontos fracos, oportunidades e ameaças que se apresentam no ambiente de negócio (BARROS, 2005). Com um diagnóstico bem apurado do ambiente interno e externo da organização, todas as principais decisões posteriores podem ter maior coerência e maior potencial de assertividade. Embora seja fato que qualquer indivíduo tenha racionalidade limitada (SIMON, 1965), o que significa que somos afetados por vieses cognitivos de nossa subjetividade e que somos incapazes de absorver todas as variáveis que podem ser afetadas por nossas decisões, o planejamento tende a minimizar os riscos de que as decisões tomadas sejam pouco coerentes com as ações necessárias à solução efetiva dos problemas. A importância do planejamento deve ser ressaltada em todas propostas de solução para os problemas com os quais o gestor da Fábrica de Sapatos Price se depara.

Na proposta que trazemos neste trabalho, a atividade pedagógica com a articulação entre análise fílmica e ABP parte de quatro principais problemas interrelacionados: (i) ausência de giro de estoque da fábrica; (ii) características do produto incompatíveis com as expectativas dos revendedores varejistas; (iii) obsolescência do processo produtivo; e (iv) não integração da diversidade à cultura organizacional. Aqui discutimos as principais reflexões que podem ser associadas a cada um destes problemas.

Em relação ao primeiro problema, é importante que as reflexões perpassem os possíveis motivos que ocasionaram decadência das vendas. Os sapatos Oxford são de um único modelo, com material de alta qualidade e transpassam uma imagem de tradicionalismo. Por que estes sapatos ficaram "encalhados" no estoque? Por que o Sr. Price omitiu dos demais funcionários a real situação da empresa, de modo que eles continuaram a produzir, da mesma forma, mesmo não havendo mercado consumidor para as mercadorias produzidas? 
Embora essas questões não apresentem respostas exatas, para que os debates avancem nas reflexões sobre as mudanças macroambientais, que impactam no ambiente microorganizacional, alguns pontos podem ser ressaltados. Ao longo das últimas décadas, especialmente após década de 1970, quando a globalização é impulsionada pela incorporação microeletrônica aos processos produtivos e pela crise do fordismo, as grandes empresas necessitaram cada vez mais incorporar diferenciais competitivos aos seus negócios. Com o aumento da competitividade, a variabilidade e a customização dos produtos criam novos comportamentos no mercado consumidor, com mudanças mais rápidas no campo da moda e com a massificação de uma cultura social em que a expressão de identidades se dá também a partir de vestimentas e uso de produtos (YANAZE, 2011). Neste contexto, a produção de um único produto padronizado pode ser um indício de que a empresa familiar retratada no filme não acompanhou essas mudanças, faltando um alinhamento entre as áreas da Administração no campo da Produção e do Marketing.

Não obstante, produzir sem vender parece indicar um grande paternalismo do Sr. Price em relação aos funcionários. Ao mesmo tempo em que parece haver relações amistosas da direção com os funcionários, as decisões são totalmente centralizadas no principal gestor, não envolvendo os demais membros da empresa em decisões que extrapolem o operacional. Além disso, após Charlie assumir a direção, as diversas demissões bruscas feitas quando toma conhecimento da situação da empresa geram impactos negativos no clima organizacional. Nota-se, portanto, que não há estímulo à criatividade e à participação dos funcionários, o que pode impactar em seu comprometimento e motivação.

Sobre o segundo problema, temos que Charlie se dá conta que a alta durabilidade de seus produtos se torna um ponto negativo para varejistas dos canais de distribuição de sua empresa. Produtos que estragam rapidamente geram o comportamento de novas compras dos consumidores - desde que essa vida útil mais curta não comprometa a imagem do produto. Uma das possibilidades de ação de Charlie, além de criar novos produtos, era produzir calçados menos duráveis. Isto, todavia, contraria totalmente os valores que o pai de Charlie tinha para si e para sua empresa: aquela fábrica que produz sapatos que duram toda 
uma vida. Assim, vale a pena seguir por esse caminho (produzir produtos mais "descartáveis") ou haveria melhores opções para Charlie? O que essa obsolescência programada (produtos que as empresas propositalmente planejam para que estraguem) diz da ética social?

Para essas questões, é importante que se reflita que a atual descartabilidade célere dos produtos, o estímulo ao consumismo que acompanha a produção ininterrupta de novos modelos e a lógica econômica que dita que o crescimento das vendas deve ser perpétuo são incompatíveis com os recursos materiais finitos de nosso planeta. Neste sentido, a obsolescência programada é inconciliável com a responsabilidade socioambiental, pois propicia o aumento do consumo de recursos naturais, maior descarte de resíduos e o enfraquecimento da consciência social sobre a necessidade de relação saudável entre ser humano e meio ambiente. Diante desse cenário, outras possibilidades seriam que a fábrica Price prosseguisse na produção de calçados duráveis e de qualidade, mas segmentando-os para outros nichos, como calçados para esportes, para tracking e/ou para o público infantil. Para não conflitar com a identidade que poderá ser vinculada à produção de botas para drag queens, marcas distintas poderiam ser criadas: uma atrelando-se ao segmento esportivo, outra ao segmento artístico. Além disso, torna-se importante que toda a cadeia de valor da empresa (que inclui seus fornecedores e seu canal de distribuição aos consumidores finais) estejam alinhados com os valores da organização (SLACK; CHAMBERS; JONHSTON, 2009).

Para o terceiro problema, que trata da obsolescência do processo produtivo, tem-se um campo fértil para discussões sobre as características que a fábrica Price expressa do modelo taylorista - como produção padronizada, com maquinário mecânico, tarefas repetitivas, com poucos produtos, foco no ambiente interno da empresa e centralização das decisões na alta cúpula da empresa - e como a modernização de seu sistema produtivo poderia incorporar características do modelo toyotista - como a produção customizada, em pequenos lotes, com maior automatização, funcionários envolvidos em círculos de qualidade, foco no ambiente externo da empresa e descentralização das decisões. Ainda tomando os problemas enfrentados por Charlie, a discussão pode perpassar pelos estilos de liderança de 
seu pai e do respectivo herdeiro. Tomando por base os sistemas administrativos de Likert (1979), nota-se que a liderança do Sr. Price era mais próxima de um estilo autoritário benevolente, enquanto a de Charlie caminha gradualmente para um estilo de liderança consultivo.

Sobre o quarto e último problema que elencamos, tratamos da questão da discriminação e ofensas que Lola sofre ao passar a fazer parte da rotina da empresa de calçados. Charlie, em vez de se preparar para introduzir a diversidade na cultura de sua organização, busca inicialmente esconder Lola de sua equipe. Sem assumir de fato a postura de líder, o gestor pouco atua para que Lola não enfrente os constrangimentos decorrentes do preconceito por ela ser transgênero, tendo que lidar com ofensas que se aproximam do assédio moral ${ }^{4}$. Segundo Schein (2009), a cultura organizacional se define pelas interações dos indivíduos e é influenciada principalmente pelo comportamento das lideranças. 0 autor destaca três níveis de análise para a compreensão dessa cultura: os artefatos visíveis (ambiente físico, veículos de comunicação, vestuário etc.), as crenças e valores expostos e as suposições básicas que embasam os comportamentos da equipe. Para que a cultura da fábrica Price pudesse incorporar a diversidade com maior recepção, as propostas de transformações culturais devem considerar esses três níveis de análise. Chama a atenção o fato de a fábrica ainda se utilizar de um alto-falante, situado no escritório que fica em nível acima do "chão de fábrica" (termo que é quase literal na fábrica retratada no filme), deixando clara a distância comunicativa. Para tornar a cultura mais receptiva e integradora, também a direção deveria se mostrar mais acessível e integrada à equipe de trabalho. Por meio de diálogos próximos, reuniões, treinamentos e estruturação de um código de ética, o estímulo à diversidade e ao maior aproveitamento do conhecimento dos trabalhadores poderiam tornar a cultura mais aberta ao novo e ao trabalho em equipe. Um ambiente organizacional mais diversificado é capaz de aprimorar a imagem organizacional que a empresa transmite, atender melhor a diversidade que compõe os perfis de consumidores e tornar mais hábil os processos de

\footnotetext{
${ }^{4} \mathrm{O}$ assédio moral "está ligado a qualquer conduta abusiva em relação a uma pessoa (seja por comportamentos, palavras, atos, gestos ou escritas) que possa acarretar um dano à sua personalidade à sua dignidade ou mesmo à sua integridade física ou psíquica" (HELOANI, 2004, p. 4).
} 
adaptação que se fazem necessários ao acompanhamento das mudanças ambientais (ALVES; GALEÃO-SILVA, 2004).

$\mathrm{Na}$ próxima seção, consolidamos a proposta pedagógica de ensino, articulando a análise fílmica e a atividade que se inspira na Aprendizagem Baseada em Problemas.

\subsection{Orientações para a aplicação da proposta interdisciplinar de ensino}

Considerando o enredo e os problemas mais relevantes apresentados no filme $A$ Fábrica de Sonhos, elaboramos uma síntese (quadro 2) da proposta pedagógica, contendo as situações problemáticas expostas na película, as sugestões de questões para debate com a turma e os eixos temáticos que seriam pertinentes que as discussões perpassassem.

Quadro 2 - Síntese da proposta pedagógica

\begin{tabular}{|c|c|}
\hline Problemas retratados e questões propostas para debate & Eixo temático da discussão \\
\hline $\begin{array}{l}\text { Problema 1. Após se dar conta do problema da ausência de } \\
\text { giro de estoque, a primeira decisão que Charlie toma é a } \\
\text { demissão de empregados. O que a queda das vendas pode } \\
\text { indicar de mudanças no perfil do mercado consumidor da } \\
\text { fábrica Price? Qual o impacto da decisão de muitas demissões } \\
\text { para o corpo de empregados restantes? O que você faria no } \\
\text { lugar de Charlie? }\end{array}$ & $\begin{array}{l}\text { - Pesquisa de mercado } \\
\text { - Diferenças geracionais } \\
\text { - Motivação } \\
\text { - Comprometimento }\end{array}$ \\
\hline $\begin{array}{l}\text { Problema 2. Ao visitar um varejista revendedor de seus } \\
\text { sapatos, Charlie se depara com o "problema" de seus produtos } \\
\text { serem muitos duráveis e, portanto, têm uma vida útil que não } \\
\text { estimula os consumidores a fazerem novas compras em curto } \\
\text { período. Nesse caso, seria interessante que o gestor buscasse a } \\
\text { fabricação de produtos com materiais mais propícios ao } \\
\text { desgaste ou outra possibilidade poderia ser adotada? O que } \\
\text { essa decisão reflete sobre os valores da empresa, dos seus } \\
\text { gestores e a coerência com a história da organização retratada? }\end{array}$ & $\begin{array}{l}\text { - Valores morais } \\
\text { - Ética social e } \\
\text { organizacional } \\
\text { - Responsabilidade } \\
\text { socioambiental } \\
\text { - Canais de distribuição } \\
\text { - Obsolescência programada } \\
\text { - Fidelização de clientes } \\
\text { - Imagem empresarial } \\
\end{array}$ \\
\hline $\begin{array}{l}\text { Problema 3. Ao longo do filme, é possível perceber que o } \\
\text { modelo produtivo na Fábrica Price tem características } \\
\text { tayloristas e que o estilo de gestão praticado na empresa antes } \\
\text { da ambientação de Charlie era pouco aberto à inovação. Essas } \\
\text { caraterísticas parecem ter influenciado a quase falência da } \\
\text { empresa. Quais são as características do Taylorismo que } \\
\text { podem ser identificadas no filme? Qual estilo de gestão é } \\
\text { predominante na liderança do Sr. Price e de Charlie? Quais os } \\
\text { prós e contras que a adoção de um modelo produtivo mais }\end{array}$ & $\begin{array}{l}\text { - Modelos produtivos } \\
\text { - Estilos de liderança } \\
\text { - Taylorismo } \\
\text { - Toyotismo } \\
\text { - Inovação }\end{array}$ \\
\hline
\end{tabular}


próximo do Toyotismo poderia trazer à gestão da fábrica Price?

Problema 4. Ao incorporar uma pessoa transgênero na força de trabalho da empresa, Charlie se depara com a situação de haver empregados que a tratam com discriminação e deboche. Quais os possíveis prejuízos econômicos e sociais dessa situação e quais decisões Charlie deveria tomar para evitar o possível assédio moral no ambiente de trabalho?

- Diversidade e diferenças

- Cultura organizacional

- Assédio moral

- Gestão da diversidade

- Minorias sociais

Fonte: elaborado pelos autores

Para a realização da atividade, recomendamos que sejam separadas, no mínimo, quatro aulas com duração de 50 minutos cada (tempo padrão para a maioria das estruturas curriculares do ensino técnico e do ensino superior). Nas duas primeiras aulas, o docente exporá o filme para a turma, deixando como instruções prévias que os discentes se atentem aos problemas administrativos que podem ser identificados na obra. As duas aulas posteriores - que poderão ocorrer no mesmo dia ou no próximo encontro que o docente tiver com a turma - serão destinadas à realização da atividade prática. Para tanto, a turma deverá ser dividida em grupos de três a seis pessoas. É importante que os grupos não sejam muito grandes, para minimizar a situação de estudantes mais inibidos não se expressarem suficientemente, e também que a atividade não seja feita individualmente, pois os debates tendem a ser uma relevante fonte de aprendizagem e de fixação do conhecimento.

Com os grupos divididos, o docente apresentará um problema por vez, disponibilizando o período de 15 minutos para a consolidação de uma resposta a cada um deles. Os grupos devem anotar a síntese das respostas condensadas em tópicos, para se lembrarem das discussões. Após os 60 minutos para a realização dos exercícios de debate sobre os quatro problemas, o docente poderá utilizar o período restante da aula (em torno de 30 a 40 minutos) para fazer um grande círculo com toda a turma, quando então cada grupo exporá a síntese do consenso que chegaram sobre os problemas apresentados. Neste momento, o docente poderá fazer observações sobre os pontos que convergiram e os pontos que divergiram entre os grupos, além de complementar o debate com questões e apontamentos sobre assuntos importantes que não foram tratados e/ou que não foram aprofundados pelos estudantes. 
Após essas discussões, como atividade para realizarem em casa ou para realização em sala no próximo encontro, há ainda a possibilidade de os estudantes, em grupo ou individualmente, elaborarem por escrito as respostas para os problemas apresentados. Para tanto, deverão considerar as reflexões em sala que julgaram como as mais importantes, elaborando as próprias respostas com base nelas. Essa etapa final pode ser um diferencial para a fixação do conhecimento e para o desenvolvimento de um maior poder de síntese dos discentes. Cumprindo todas essas etapas, a atividade pedagógica em questão terá atuado, para além da aplicação prática das teorias administrativas, no auxílio ao aprimoramento das seguintes competências discentes: pensamento crítico, visão interdisciplinar, observação analítica, trabalho em equipe, expressão oral, expressão escrita e capacidade de síntese de resultados.

\section{Considerações Finais}

Esta pesquisa trouxe como parte de seus resultados a análise fílmica de $A$ Fábrica de Sonhos, considerando os elementos mais relevantes da obra e suas analogias às teorias da Administração. A partir da análise fílmica, vários foram os problemas identificados, os quais serviram de exemplos bastante ilustrativos para a abordagem de teorias da Administração e de reflexões de cunho ético e social. Deste modo, foram feitas orientações para uma proposta interdisciplinar de ensino, objetivando discussões e fixação do conhecimento por meio de problemas retratados na arte audiovisual. A proposta apresentada poderá suscitar debates sobre diferenças geracionais, motivação, valores morais, responsabilidade socioambiental, cultura organizacional, fidelização de clientes, diversidade e diferenças, dentre outros.

Esta pesquisa apresenta como contribuição principal a articulação entre metodologias ativas de aprendizagem e análise fílmica, o que pode servir de inspiração não apenas para o ensino em Administração como também para outras áreas do conhecimento. Levando em conta a interdisciplinaridade e a aplicação prática das teorias a situações verossímeis à rotina do administrador, defendemos que propostas desta natureza propiciam o efetivo desenvolvimento de competências aos discentes. 
Um desafio importante para maior incorporação de práticas pedagógicas diversificadas, em áreas do conhecimento não vinculadas à educação básica, é a própria formação docente. Programas de mestrado e doutorado de áreas tecnológicas e das ciências sociais aplicadas, em geral, pouco trazem de conteúdo especificamente voltado para a capacitação pedagógica e didática dos futuros docentes. Privilegiando a formação de pesquisadores(as), carece nos programas de pós-graduação stricto sensu um comprometimento sólido com a formação de professores(a), para que mais estudos, como este, sejam estimulados.

Neste ínterim, sugerimos que novos estudos e propostas pedagógicas, relacionando a Aprendizagem Baseada em Problemas e análise fílmica, sejam realizados. Com o comprometimento docente para o aperfeiçoamento da experiência de aprendizagem dos estudantes e para o maior foco no contexto sócio-histórico para o debate de teorias, a tendência é que o pensamento crítico seja estimulado e que a formação educacional seja mais abrangente e integrada à melhoria do convívio social.

\section{REFERÊNCIAS}

ABUD, K. M. A construção de uma Didática da História: algumas idéias sobre a utilização de filmes no ensino. História, Franca, v. 22, n. 1, p. 183-193, 2003.

ALVES, M. A.; GALEÃO-SILVA, L. G. A crítica da gestão da diversidade nas organizações. Revista de Administração de Empresas, v. 44, n. 3, p. 20-29, 2004.

ARIAS, J. O. C.; YERA, A. P. 0 que é a Pedagogia Construtivista? Revista de Educação Pública, Cuiabá, v. 5, n. 8, jul./dez., 1996.

BARROS, A. Gestão estratégica nas pequenas e médias empresas. Rio de Janeiro: Editora Ciência Moderna, 2005. 
BARROS, M. J. F.; MIRANDA, E. M.; RODRÍGUEZ, V. B. C. O Uso do Filme de Animação no Ensino de Administração Monstros S.A. como Estudo de Caso Exemplar. Revista Gestão \& Planejamento, v. 18, n. 1, p. 160-181, 2017.

BOROCHOVICIUS, E.; TORTELLA, J. C. B. Aprendizagem Baseada em Problemas: um método de ensino-aprendizagem e suas práticas educativas. Ensaio: Avaliação e Políticas Públicas em Educação, Rio de Janeiro, v. 22, n. 83, p. 263-294, jun., 2014.

BUTLER, J. Problemas de gênero: feminismo e subversão da identidade. Rio de Janeiro: Civilização Brasileira. 2003.

CASAlE, A.; KURI, N. P.; SILVA, A. N. R. Mapas cognitivos na avaliação da Aprendizagem Baseada em Problemas. Revista Portuguesa de Educação, v. 24, n. 2, p. 243-263. 2011.

FLEURY, M. T. L.; SARSUR, A. M. O quadro-negro como tela: o uso do filme Nenhum a menos como recurso de aprendizagem em gestão por competências. Cadernos EBAPE.BR, Rio de Janeiro, v. 5, n. 1, p. 01-17, mar., 2007.

FRANCO, D. S.; PAIVA, K. C. M.; HELMOND, S. C. Possibilidades e Desafios para Uma Abordagem Andragógica no Ensino em Administração e Contabilidade. Revista ADM.MADE, v. 19, n. 3, p. 16-33, 2015.

FREIRE, P. Pedagogia do Oprimido. 45 ed. Rio de Janeiro: Paz e Terra, 2005.

GOERGEN, P. L. Educação Moral hoje: cenários, perspectivas e perplexidades. Educação e Sociedade, v. 28, p. 737-762, 2007.

GUEDES, K. L.; ANDRADE, R. O. B.; NICOLINI, A. M. A avaliação de estudantes e professores de Administração sobre a experiência com a aprendizagem baseada em problemas. Administração: Ensino e Pesquisa, v. 16, n. 1, p. 71-71, 2015.

HELOANI, R. Assédio moral - Um ensaio sobre a expropriação da dignidade no trabalho. RAEeletrônica, v. 3, n. 1, art. 12, p. 1-18, 2004. 
ISBOLI, G. H. P.; PÉPECE, O. M. C.; GAIOTTO, S. A. V. Films as Object of Studies for Research in Applied Social Sciences. Reuna, v. 22, n. 3, p. 60-73, 2017.

LIKERT, R. Novos padrões de administração. 2. ed. São Paulo: Pioneira, 1979.

MACIEL, H. W. P.; HELAL, D. H. "Detalhes de sua Incompetência não me Interessam": 0 Assédio Moral no Filme O Diabo Veste Prada. REAd. Revista Eletrônica de Administração, v. 23, n. N. Especial, p. 412-427, 2017.

MENDONÇA, R.; GUIMARÃES, F. P. Do quadro aos "quadros": o uso de filmes como recurso didático no ensino de administração. Cadernos EBAPE.BR, v. 6, n. Ed. Especial, art. 2, p. 1-21, 2008.

MUNCK, L.; BORGES, M. Aprendizagem, Desenvolvimento de Competências e Reflexões sobre o Aprender: Relato de Experiência Utilizando Aprendizado mais Profundo e Metodologias Ativas. Revista Alcance, v. 27, n. 1, p. 4-17, 2020.

PÁDUA JÚNiOR, F. P.; CASTILHO FILHO, J. P.; STEINER NETO, P. J.; AKEL SOBRINHO, Z. Avaliação da percepção de discentes e docentes sobre novas tecnologias de ensino em cursos de graduação em Administração. Administração: Ensino e Pesquisa, v. 15, n. 2, p. 295-321, 2014.

SCHEIN, Edgar H., Cultura Organizacional e Liderança. 3a ed. São Paulo: Atlas, 2009.

SIMON, H. Comportamento administrativo. Rio de Janeiro: FGV, 1965.

SLACK, N.; CHAMBERS, S.; JONHSTON, R. Administração da produção. 3.ed. São Paulo: Editora Atlas, 2009.

SOARES, J. M. M. V. et al. Metodologias Ativas de Ensino: Evidências da Aplicação do Método de Caso nos Cursos de Ciências Contábeis e Administração. Revista Mineira de Contabilidade, v. 20, n. 3, p. 92-103, 2019. 
VERSIANI, A.; FACHIN, R. Avaliando aprendizagem em simulações empresariais. Cadernos EBAPE.BR, v. 5, n. Ed. Especial, p. 1-13, 2007.

YANAZE, M. H. Gestão de Marketing e Comunicação: avanços e aplicações. 2.Ed. São Paulo: Saraiva, 2011. 